\title{
Real-World 1-Year Retention Rate of Subcutaneous Tocilizumab Treatment in Patients with Moderate to Severe Active Rheumatoid Arthritis: TANDEM Study
}

\author{
Pascal Hilliquin · Thomas Barnetche $\cdot$ Athan Baillet $\cdot$ René-Marc Flipo · \\ Eric Lespessailles - Christian Roux · Patrice Fardellone · \\ Anika Gilbert-Marceau · Isabelle Idier · Arnaud Constantin · \\ Emilie Shipley $\cdot$ Guy Baudens · Alain Saraux
}

Received: August 27, 2020 / Accepted: November 3, 2020 / Published online: November 20, 2020

(C) The Author(s) 2020

\begin{abstract}
Introduction: Drug retention is particularly relevant to assess long-term treatments. This real-world study mainly aimed to describe 1-year retention rate (RR) of subcutaneously administered tocilizumab (TCZ-SC) in patients with moderate to severe active rheumatoid arthritis (RA).
\end{abstract}

P. Hilliquin $(\bowtie)$

Rheumatology Department, C.H. Sud Francilien, Corbeil-Essonnes, France

e-mail: pascal.hilliquin@chsf.fr

T. Barnetche

Rheumatology Department, University Hospital of Bordeaux, FHU ACRONIM, Bordeaux, France

A. Baillet

Rheumatology Department, University Hospital of Grenoble, Grenoble, France

R.-M. Flipo

Rheumatology Department, University Hospital of Lille, Lille, France

E. Lespessailles

Rheumatology Department, General Hospital of

Orléans, Orléans, France

C. Roux

Rheumatology Department, University Hospital of

Nice, Nice, France

P. Fardellone

Rheumatology Department, University Hospital of

Amiens, Amiens, France
Methods: This non-interventional, prospective, multicenter study (NCT02608112) was conducted in patients with RA initiating TCZ-SC treatment, with an 18-month follow-up. RR was estimated at month 12 in the overall population and baseline subgroups (combination with a conventional synthetic disease-modifying antirheumatic drug (csDMARD) or not, age, body mass index, methotrexate dose), using the Kaplan-Meier method. Patient compliance to

\section{A. Gilbert-Marceau}

Medical Data Department, Roche SAS, BoulogneBillancourt, France

\section{Idier}

Medical Affairs, Chugai Pharma France, Paris La Défense, Puteaux, France

\author{
A. Constantin \\ Rheumatology Department, University Hospital of \\ Toulouse, Toulouse, France \\ E. Shipley \\ Rheumatology Department, General Hospital of \\ Dax, Dax, France \\ G. Baudens \\ Rheumatology, Private Practice, Valenciennes, \\ France

\section{A. Saraux} \\ Rheumatology Department, CHU de Brest, Univ \\ Brest, Inserm UMR1227, Lymphocytes B et \\ Autoimmunité, Brest, France
}


TCZ-SC was described using the 5-item Compliance Questionnaire for Rheumatology (CQR5).

Results: At inclusion $75 \%$ of the 285 analyzed patients were women, mean RA duration was $9 \pm 9$ years, previous RA treatments included biological agents (63\%) and/or csDMARDs (94\%), mean Disease Activity Score 28 jointsErythrocyte Sedimentation Rate (DAS28-ESR) was $4.8 \pm 1.2$. TCZ-SC RR at month 12 was estimated to be $64 \%$ (95\% CI 58\%-69\%) with no statistical differences between subgroups. Clinical results improved with TCZ-SC; the proportion of patients treated with combined glucocorticoids decreased from $49 \%$ to $22 \%$ at month 12. At each follow-up time, at least $80 \%$ of patients were high adherers to TCZ-SC (at least $80 \%$ of theoretical injections). Among the 286 patients with at least one TCZ-SC injection, 25 patients (9\%) experienced serious adverse events related to TCZ-SC with no differences according to patient age.

Conclusions: This real-world study corroborates the RR at month 12 previously shown in interventional studies on TCZ-SC. Our data suggest there are no differences according to patient's profile (age, BMI), methotrexate doses, and TCZ-SC use.

Trial Registration: NCT02608112.

Keywords: Biological therapy; Diseasemodifying antirheumatic drugs; Rheumatoid arthritis; Tocilizumab

\section{Key Summary Points}

Non-interventional, prospective, multicenter study conducted in 286 patients with rheumatoid arthritis (RA) initiating subcutaneous tocilizumab (TCZSC) treatment in real life.

At 12 months, drug retention rate was estimated to be $64 \%$ (95\% CI 58\%-69\%) with no statistical differences between the following subgroups.
Use of TCZ-SC as monotherapy or with combined conventional synthetic diseasemodifying antirheumatic drug (csDMARD).

Patient age.

Body mass index.

Different weekly methotrexate doses.

No relevant differences were obtained in safety analyses when comparing patients older than 65 years to younger patients with similar rates of adverse events (AEs) related to TCZ-SC, related serious adverse events (SAEs), and serious adverse events of special interest (AESIs).

\section{DIGITAL FEATURES}

This article is published with digital features, including a summary slide, to facilitate understanding of the article. To view digital features for this article go to https://doi.org/10.6084/ m9.figshare.13182962.

\section{INTRODUCTION}

Tocilizumab (TCZ) is the first humanized monoclonal antibody inhibiting both soluble and membrane-bound interleukin-6 receptors, approved worldwide for the treatment of rheumatoid arthritis (RA). Findings from previous clinical trials showed the efficacy and safety of the intravenous formulation of TCZ (TCZ-IV) in combination with methotrexate (MTX) [1-5], and in monotherapy $[4,6,7]$. These experimental data were confirmed in a real-life setting [8-11]. Subsequently to the positive results of clinical trials that assessed the subcutaneous TCZ formulation (TCZ-SC) [12-14], TCZ-SC was approved in Europe in 2014. In France, once the initial prescription is issued in hospital, the prescription of TCZ-SC can be renewed by hospital- and office-based specialists. 
As drug retention (time to drug discontinuation) reflects efficacy, tolerability, and patient satisfaction, this measure is increasingly being evaluated for biological agents in RA [15-20]. Such findings are particularly relevant in unselected populations of patients taking their treatments as usually prescribed. The 1-year drug retention rate of TCZ-IV ranged between $64 \%$ and $71 \%$ in a real-life setting $[10,11,18]$ but no data on treatment persistence were available for TCZ-SC at the time of this study implementation.

In this context, the TANDEM study primarily aimed to estimate the 1-year TCZ-SC retention rate under real-world conditions in patients with moderate to severe active RA followed by hospital- and office-based rheumatologists. Secondary objectives included the description of TCZ-SC use, TCZ-SC effectiveness and safety, TCZ-SC compliance, and patient quality of life.

\section{METHODS}

\section{Study Design}

This non-interventional, multicenter, prospective cohort study was managed in cooperation with an independent scientific committee including one methodologist and one officebased and three hospital-based rheumatologists.

Included patients were followed over an 18-month period, with data collected at followup visits around months $3,6,9,12$, and 18 when performed.

According to French legislation regarding non-interventional studies, the TANDEM protocol (NCT02608112) was approved by the “Comité Consultatif sur le Traitement de l'Information en Matière de Recherche dans le Domaine de la Santé" (Consultative Committee on Information Processing for Research in the Field of Health) and by the Ethic Committee "Commission Nationale de l'Informatique et des Libertés" (Independent Administrative Authority Protecting Privacy and Personal Data) (authorization DR-2015-415), which guarantees confidentiality to the subjects. All patients were informed about the study before enrollment and had no objection to sharing their data. This study was performed in accordance with the Helsinki Declaration of 1964 and its later amendments.

\section{Physicians}

From the 1675 hospital- and office-based rheumatologists regularly managing patients with RA who were invited to participate in the study, 189 physicians (11\%) agreed, and 107 $(6 \%)$ investigators included at least one eligible patient in the TANDEM study from December 2015 to December 2016. The last patient last visit was performed on July 2018. Amongst the 94 main sites $(88 \%)$ that participated in this real-world study, 10 (11\%) delegated patient follow-up to at least one satellite site, i.e., after the first TCZ-SC prescription from hospital (done in France for all patients with RA), patients could be followed by an office-based rheumatologist if they usually did so.

\section{Patients}

Patients eligible for the study were adults for whom the specialist decided to initiate treatment with TCZ-SC (either in combination with a csDMARD or in monotherapy) for moderate to severe RA prior to inclusion and who agreed to participate. Previous treatment with TCZ and participation in a clinical trial on RA were exclusion criteria.

\section{Assessments}

At inclusion, upon initiation of TCZ-SC treatment, the following data were collected: patient's characteristics, medical history, RA history and previous treatments, disease activity [Disease Activity Score 28 joints-Erythrocyte Sedimentation Rate (DAS28-ESR), Simple Disease Activity Index (SDAI), Clinical Disease Activity Index (CDAI), patient's and physician's visual analogue scale (VAS) on global assessment of disease activity], and use of TCZ-SC.

During the follow-up visits (around months $3,6,9,12$, and 18), use of TCZ-SC and other RA treatments, RA activity, and adverse events (AEs), including AEs of special interest 
(AESIs: anaphylaxis/hypersensitivity reactions, demyelinating disorders, gastrointestinal perforations, malignancies, myocardial infarctions, strokes, and serious and/or medically significant infections, hepatic events, and bleeding events) were collected.

During the study, patients completed selfreported questionnaires to describe their disability, quality of life, and TCZ-SC compliance, using respectively the Health Assessment Questionnaire Disability Index (HAQ-DI) at inclusion, around months 6 and 12, the EuroQol Group-5 Dimensions 3 Levels (EQ-5D-3L, dimensions: mobility, self-care, usual activities, pain/discomfort, and anxiety/depression) at inclusion, around months 3,6 , and 12 , and the 5-item Compliance Questionnaire for Rheumatology (CQR5) at inclusion, around months 3 , 6, 12, and 18 .

\section{Study Size and Statistical Methods}

The primary criterion of this descriptive study was defined as the proportion of patients still receiving TCZ-SC 12 months after the first injection. Based on literature data on TCZ-IV, a drug retention rate of $65 \%$ was expected for TCZ-SC at month 12 [15]. Under this assumption, 286 patients with RA had to be included to meet the study's primary objective with an absolute precision of $\pm 6.0 \%$ and a $95 \%$ confidence interval (CI), and assuming $15 \%$ of unevaluable patients for the primary criterion.

Statistical analyses were performed using SAS $^{\circledR}$ software (version 9.4). All tests were twosided with an $\alpha$ risk at $5 \%$.

Efficacy analyses were carried out on the population of included patients having signed an informed consent and with at least one documented TCZ-SC injection (efficacy population). Safety data were analyzed on the population of patients having signed an informed consent and with at least one TCZ-SC injection (safety population).

The drug retention rate was estimated in the overall efficacy population at each follow-up time point, using the Kaplan-Meier method. The associated 95\% CI was provided using the Greenwood formula. The drug retention rate was also estimated in patient subgroups defined at inclusion (i.e., at the time of the first TCZ-SC injection): modality of use of TCZ-SC (monotherapy, MONO; with combined csDMARDs, COMBO), patient age $(\leq 65$ years, $>65$ years), body mass index (BMI; $\leq 30 \mathrm{~kg} / \mathrm{m}^{2}$, $>30 \mathrm{~kg} / \mathrm{m}^{2}$ ), weekly MTX dose (no MTX, less than $10 \mathrm{mg}$, between 10 and $15 \mathrm{mg}$, between 15 and $20 \mathrm{mg}$, and more than $20 \mathrm{mg}$ ). Betweengroup comparisons were performed using logrank tests.

All the TCZ-SC effectiveness parameters were described at each study time point. The proportions of patients in DAS28-ESR remission and low disease activity (LDA) $(<2.6$ and $\leq 3.2$, respectively), SDAI remission and LDA $(\leq 3.3$ and $\leq 11)$, and CDAI remission and LDA $(\leq 2.8$ and $\leq 10$ ) were notably described during follow-up (analyses performed on observed data). Patient-reported outcomes (HAQ-DI, EQ-5D-3L, and CQR5) were described at each study time point according to authors' recommendations. Considering CQR5, high adherers to TCZ-SC were defined by an injection rate of at least $80 \%$ of the theoretical injections.

Safety data were described in the overall safety population and according to the use of TCZ-SC (MONO and COMBO) and the patient's age at first injection ( \pm 65 years). For serious AEs (SAEs), the incidence rates were also provided per 100 patient-years (PY).

\section{RESULTS}

\section{Physicians, Population, Patient, and Rheumatoid Arthritis Characteristics at Baseline}

One hundred and seven physicians included 291 patients, $2[1 ; 4]$ for principal sites and $1[1$; 1] for satellite sites (median [Q1; Q3]), respectively. Of the 291 patients included, 286 (98\%) received at least one TCZ-SC injection (safety population), and 285 (98\%) fulfilled all the selection criteria (efficacy population) (Fig. 1).

One hundred thirty-eight patients from the safety population $(48 \%)$ did not complete the study (at month 18), mainly due to adverse 


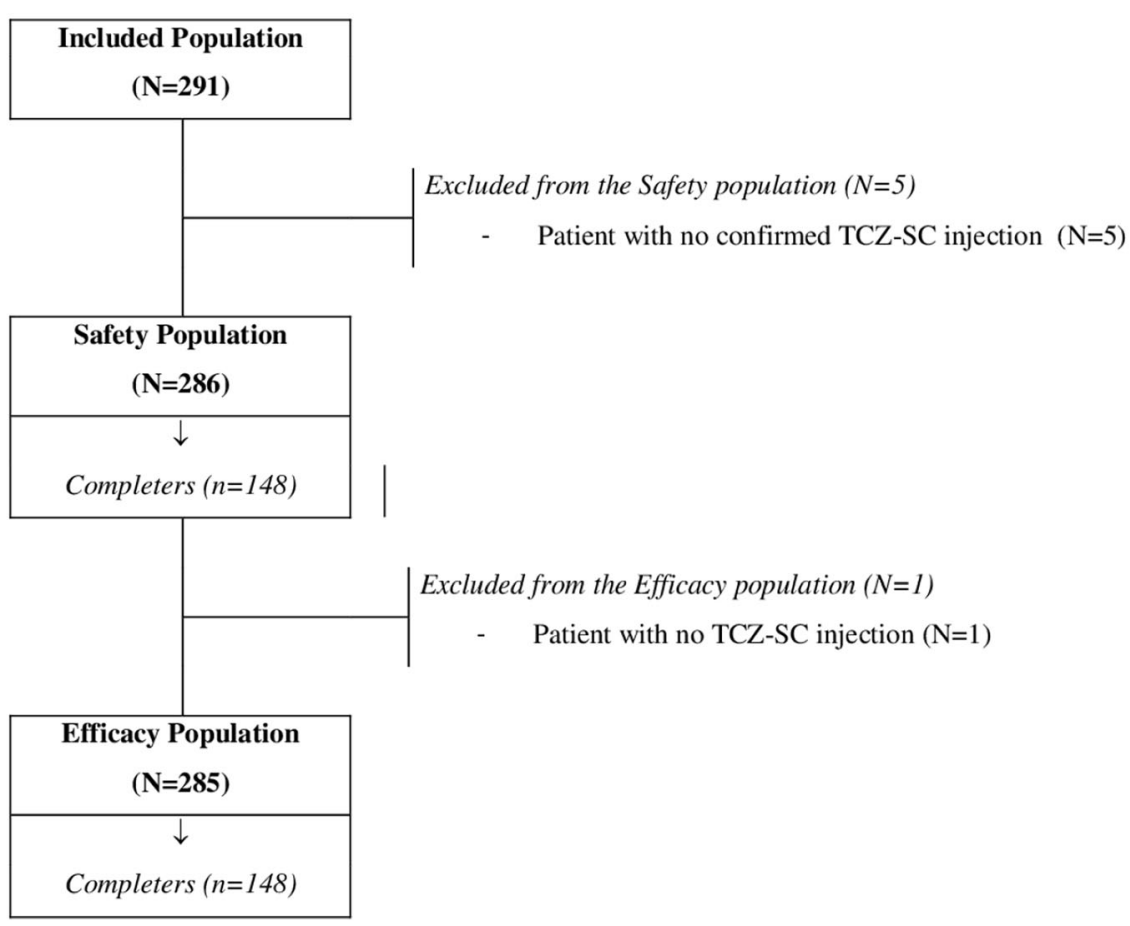

Fig. 1 Population flow chart

events $(n=61)$ or lack of treatment efficacy $(n=37)$.

Patient subgroups according to baseline parameters (use of TCZ-SC, patient age, BMI, weekly MTX dose) are detailed in Table 1. Baseline patient and RA characteristics are presented in Table 2.

Patient mean age was $56 \pm 13$ years and $75 \%$ were women. Prior to inclusion, $94 \%$ of patients received at least one csDMARD (MTX: 91\%) and $63 \%$ received at least one prior bDMARD.

At the time of the first TCZ-SC injection, the mean DAS28-ESR was $4.77 \pm 1.21$. Compared to the COMBO group, MONO patients were older ( $58 \pm 13$ vs. $55 \pm 12$ ), had longer RA duration (10.6 \pm 9.7 vs. $8.7 \pm 8.4$ years), had received prior bDMARD more frequently (70\% vs. $58 \%$ ), and had higher disease activity as assessed by patients $(62 \pm 20$ vs. $58 \pm 17 \mathrm{~mm})$. Comorbidities distribution and BMI were comparable between groups.

\section{Drug Retention}

After month 12, TCZ-SC was permanently discontinued in 119 patients (42\%). At month 12 the rate of drug retention was estimated to be $64 \%$ (95\% CI 58-69\%). At month 18 it was at $57 \%$ (95\% CI 51-63\%).

The rates of TCZ-SC retention were similar at month 12 whatever the patient and RA treatment at baseline. In particular no differences were observed between the MONO and COMBO groups [RR at 63\% (95\% CI 53-70\%) and 64\% (56-71\%), respectively ( $p=0.725$ ) (Fig. 2a)] or according to the patient's age [RR at 64\% (95\% CI 57-70\%) and 61\% (49-72\%) for respectively $\leq 65$ and $>65$ years groups $(p=0.698)$ (Fig. 2b)]. Similar findings were shown according to other patient subgroups: RR at $65 \%(95 \%$ CI $58-71 \%$ ) and $59 \%$ (45-70\%) for $\leq 30 \mathrm{~kg} / \mathrm{m}^{2}$ and $>30 \mathrm{~kg} / \mathrm{m}^{2}$ BMI groups, respectively $(p=0.496) \quad$ (Fig. 2c); RR from 62\% (95\% CI $54-70 \%)$ to $68 \%(55-78 \%)$ for respectively 0 to $\geq 20 \mathrm{mg} /$ week MTX dose classes ( $p$ value between 0.781 and 0.995 depending on the dose used) (Fig. 2d). 
Table 1 Patient subgroups of interest efficacy population $(N=285)$

\begin{tabular}{ll}
\hline & Total, $N=\mathbf{2 8 5}$ \\
& $\boldsymbol{N}(\mathbf{\%})$ \\
\hline TCZ-SC use at first injection & $(n=282)$ \\
MONO & $124(44.0)$ \\
COMBO & $158(56.0)$ \\
Age class & \\
$\leq 65$ years & $216(75.8)$ \\
$>65$ years & $69(24.2)$ \\
BMI class & $(n=269)$ \\
$\leq 30 \mathrm{~kg} / \mathrm{m}^{2}$ & $212(78.8)$ \\
$>30 \mathrm{~kg} / \mathrm{m}^{2}$ & $57(21.2)$ \\
MTX dose class at first TCZ-SC injection \\
0 mg/week & $151(53.0)$ \\
$>0$ to $<10 \mathrm{mg} /$ week & $2(0.7)$ \\
$\geq 10$ to $<15 \mathrm{mg} /$ week & $17(6.0)$ \\
$\geq 15$ to $<20 \mathrm{mg} /$ week & $49(17.2)$ \\
$\geq 20 \mathrm{mg} /$ week & $66(23.2)$ \\
\hline
\end{tabular}

$B M I$ body mass index, COMBO TCZ-SC in combination with conventional synthetic disease-modifying antirheumatic drug at first TCZ-SC injection, MONO TCZ-SC monotherapy at first TCZ-SC injection, MTX methotrexate, TCZ-SC subcutaneously administered tocilizumab

\section{Subcutaneous Injections of Tocilizumab}

TCZ-SC injections were mainly administered at home (8205/8829 injections, 93\%) by patients themselves or family members/friends in most of the cases (54\% and $11 \%$, respectively) or by nurses $(35 \%)$, whereas only $7 \%$ of injections $(n=624)$ were administered at hospital or by an office-based rheumatologist/nurse.

On the basis of the CQR5 questionnaire, more than $80 \%$ of patients were "high adherers" to TCZ-SC injections, whatever the follow-up time point was. This was the case for $88 \%$ of
Table 2 Patient and disease characteristics at baseline: efficacy population $(N=285)$

\begin{tabular}{|c|c|}
\hline & Total, $N=285$ \\
\hline \multicolumn{2}{|l|}{ Patients' characteristics } \\
\hline Age (years), mean $\pm S D$ & $56.3 \pm 12.5$ \\
\hline Women, no. (\%) & $213(74.7)$ \\
\hline BMI $\left(\mathrm{kg} / \mathrm{m}^{2}\right)$, mean $\pm \mathrm{SD}$ & $\begin{array}{l}26.3 \pm 5.4 \\
\quad(n=269)\end{array}$ \\
\hline \multicolumn{2}{|l|}{ Past or concomitant diseases } \\
\hline $\begin{array}{l}\text { Patients with at least one past or concomitant } \\
\text { disease, no. (\%) }\end{array}$ & $205(71.9)$ \\
\hline \multicolumn{2}{|l|}{ RA history } \\
\hline RA duration (years), mean $\pm S D$ & $9.4 \pm 9.0$ \\
\hline Positive RF or ACPA, no. (\%) & $\begin{array}{l}236(83.4) \\
\quad(n=283)\end{array}$ \\
\hline Erosive RA*, no. (\%) & $\begin{array}{l}172(60.8) \\
\quad(n=283)\end{array}$ \\
\hline Structural damage**, no. (\%) & $87(32.7)(n=266)$ \\
\hline \multicolumn{2}{|l|}{ Previous RA treatment } \\
\hline \multicolumn{2}{|l|}{ csDMARDs } \\
\hline At least one prior csDMARD, no. (\%) & $269(94.4)$ \\
\hline Number of previous csDMARDs, mean \pm SD & $\begin{array}{l}1.8 \pm 1.0 \\
\quad(n=269)\end{array}$ \\
\hline Previous MTX, no. (\%) & $259(90.9)$ \\
\hline Started 2 years prior to inclusion, no. (\%) & $83(33.5)(n=248)$ \\
\hline At least one other prior csDMARD, no. (\%) & $142(49.8)$ \\
\hline \multicolumn{2}{|l|}{ bDMARDs } \\
\hline At least one prior bDMARD, no. (\%) & $179(62.8)$ \\
\hline Number of previous bDMARDs, mean \pm SD & $\begin{array}{l}1.8 \pm 0.9 \\
\quad(n=179)\end{array}$ \\
\hline \multicolumn{2}{|l|}{ Oral glucocorticoids } \\
\hline At least one prior oral glucocorticoid, no. (\%) & $\begin{array}{l}215(75.7) \\
\quad(n=284)\end{array}$ \\
\hline $\begin{array}{l}\text { Delay between last dose and inclusion (years), } \\
\text { mean } \pm S D\end{array}$ & $\begin{array}{l}1.4 \pm 3.2 \\
\quad(n=208)\end{array}$ \\
\hline \multicolumn{2}{|l|}{ Other treatments for $\mathrm{RA}^{\#}$} \\
\hline At least one prior other treatment, no. (\%) & $\begin{array}{l}194(68.6) \\
\quad(n=283)\end{array}$ \\
\hline $\begin{array}{l}\text { Concomitant RA treatments at first TCZ-SC } \\
\text { injection, no. (\%) }\end{array}$ & $(n=282)$ \\
\hline MTX & $134(47.5)$ \\
\hline At least one other csDMARD & $28(9.9)$ \\
\hline Oral glucocorticoid & $138(48.9)$ \\
\hline \multicolumn{2}{|l|}{$\mathrm{RA}$ characteristics at inclusion, mean $\pm \mathrm{SD}$} \\
\hline DAS28-ESR & $\begin{array}{l}4.77 \pm 1.21 \\
\quad(n=252)\end{array}$ \\
\hline SDAI & $\begin{array}{l}25.43 \pm 11.42 \\
\quad(n=246)\end{array}$ \\
\hline CDAI & $\begin{array}{c}23.90 \pm 10.76 \\
(n=256)\end{array}$ \\
\hline HAQ-DI standard score & $\begin{array}{r}1.32 \pm 0.69 \\
(n=261)\end{array}$ \\
\hline
\end{tabular}


Table 2 continued

\begin{tabular}{lc}
\hline & Total, $\boldsymbol{N}=\mathbf{2 8 5}$ \\
\hline Global assessment of disease activity (physicians' & $55.2 \pm 19.6$ \\
VAS, mm) & $(n=257)$ \\
Global assessment of disease activity (patients' & $58.4 \pm 22.3$ \\
VAS, mm) & $(n=279)$ \\
EQ-5D-3L-index score & $0.38 \pm 0.33$ \\
& $(n=257)$ \\
\hline
\end{tabular}

$A C P A$ anti-citrullinated protein antibody, $B M I$ body mass index, $C D A I$ Clinical Disease Activity Index, $c s / b D M A R D$ conventional synthetic/biologic disease-modifying antirheumatic drug, DAS28-ESR Disease Activity Score 28 joints-Erythrocyte Sedimentation Rate, EQ-5D-3L EuroQol Group-5 Dimensions 3 Levels, HAQ-DI Health Assessment Questionnaire-Disability Index, $M T X$ methotrexate, $R A$ rheumatoid arthritis, $R F$ rheumatoid factor, $S D$ standard deviation, $S D A I$ Simplified Disease Activity Index, $T C Z-S C$ subcutaneously administered tocilizumab, $V A S$ visual analogue scale

${ }^{*}$ Worsening at X-ray during RA at any time

** Worsening at $\mathrm{X}$-ray over the past 2 years

\# Nonsteroidal anti-inflammatory drugs [152/283 (53.3\%)] or infiltration with corticosteroids $[106 / 283(37.2 \%)]$ or intramuscular corticosteroids $[3 / 283(1.1 \%)]$ or intravenous bolus corticosteroids [33/283 (11.6\%)]

treated patients (100/114 patients) at month 6 and $87 \%(77 / 99)$ at month 12.

\section{Effectiveness}

Strong improvements from baseline were observed with TCZ-SC for DAS28-ESR, SDAI, CDAI, and HAQ-DI (Table 3). In addition, a glucocorticoid-sparing effect was shown: $49 \%$ of the patients took concomitant oral glucocorticoids at the first TCZ-SC injection, at a daily dose $\leq 5 \mathrm{mg}$ eq. prednisone for $39 \%$ of them $(n=52)$. At month $12,22 \%$ of patients received glucocorticoids. There was no difference between $\mathrm{MONO}$ and $\mathrm{COMBO}$ groups whether at inclusion or at month 12 .

\section{PRO}

According to the EQ-5D-3L questionnaire, the quality of life of patients improved concomitantly, from $0.38 \pm 0.33$ at inclusion to $0.65 \pm 0.26$ at month 12. In particular, the proportion of patients with no problems increased from $39 \%$ at baseline to $61 \%$ at month 6 , and $66 \%$ at month 12 (102/260, $86 / 141$ and 70/106 patients, respectively).
Safety

The 286 patients in the safety population had a median follow-up of 16.7 months (range 0.0-24.5). Amongst them, $82 \%$ experienced at least one $\mathrm{AE}$ and $729 \mathrm{AEs}$ were reported. The most common AEs were infections and infestations occurring in $42 \%$ of the patients (MONO $38 \%$, COMBO $46 \%$ ), bronchitis being the most frequently reported $(10 \%)$. Seventeen patients (6\%) experienced at least one injection site reaction, erythema being the most frequently reported.

Twenty-two percent of the patients experienced 86 AEs leading to treatment withdrawal (gastrointestinal disorders in 6\% of the patients; skin and subcutaneous tissue disorders in 4\%; infections and infestations in 3\%). One local reaction led to treatment discontinuation.

A total of 25 patients (9\%) experienced at least one SAE related to TCZ-SC and 32 related SAEs were reported. The overall SAE rate was 21.4 cases per $100 \mathrm{PY}$, with a lesser incidence in the MONO group (15 cases/100 PY vs. 27 cases/ $100 \mathrm{PY}$ in the COMBO group). The most frequent SAEs were infections and infestations (ten events reported in eight patients, 3\%). The incidence rate of serious infections and infestations was 4.3/100 PY, this incidence being more than twice lower in the MONO group than in the COMBO group (2.3/100 PY and 5.8/ $100 \mathrm{PY}$, respectively).

Sixty-seven percent of the patients experienced 375 AESIs; infections and infestations were the most frequently reported (42\%), followed by neutropenia and associated complications (10\%), anaphylactic reactions as angioedema/urticarial (6\%) and as gastrointestinal symptoms (5\%).

One fatal non-related $\mathrm{AE}$ was reported during the safety reporting period (small cell lung cancer) and one death (pleuropneumopathy followed by cardiac insufficiency in a 82-yearold patient), assessed as related to TCZ-SC, occurred around 8 months after treatment discontinuation.

Focusing on patient age (Table 4), the proportions of patients with at least one $\mathrm{AE}$ or at least one AE related to TCZ-SC according to investigators were similar whatever the age 
TCZ-SC retention rate by TCZ-SC use at first injection

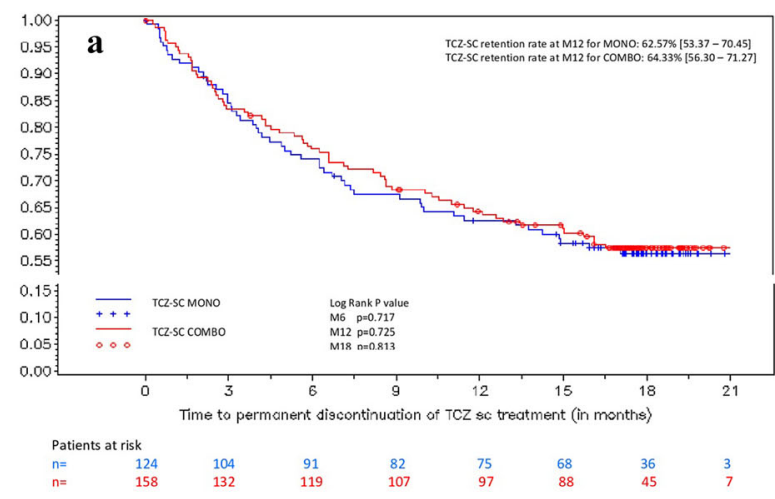

TCZ-SC drug retention rate by patient BMI

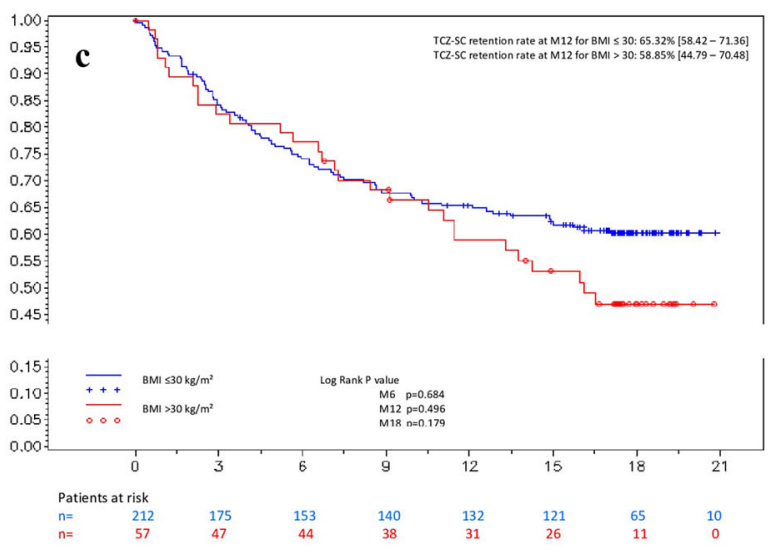

Fig. 2 Kaplan-Meier curves of subcutaneously administered tocilizumab retention rate by groups of interest: efficacy population $(N=285)$. a TCZ-SC retention rate by TCZ-SC use at first injection. b TCZ-SC drug

group ( $\leq 65$ years: $81 \%$ and $56 \%$, respectively; $>65$ years: $84 \%$ and $57 \%$ ). Overall, $22 \%$ of patients discontinued TCZ-SC for safety reasons ( $\leq 65$ years: $20 \% ;>65$ years: $26 \%$ ). Older patients experienced more AESIs (74\% vs. 64\%) but no differences between age groups were observed for serious AESIs (9.7\% vs. 10\%). Older patients also experienced more SAEs $(21 \%$ vs. $14 \%)$ but a similar proportion of patients with treatment-related SAEs was observed between age groups ( $10 \%$ vs. $8 \%$ ).

Regarding infections and infestations, no differences were observed between age groups (AEs: $\leq 65$ years $43 \%$, > 65 years 39\%; related AEs: $23 \%$ and $21 \%$; SAEs: $4 \%$ in both groups).
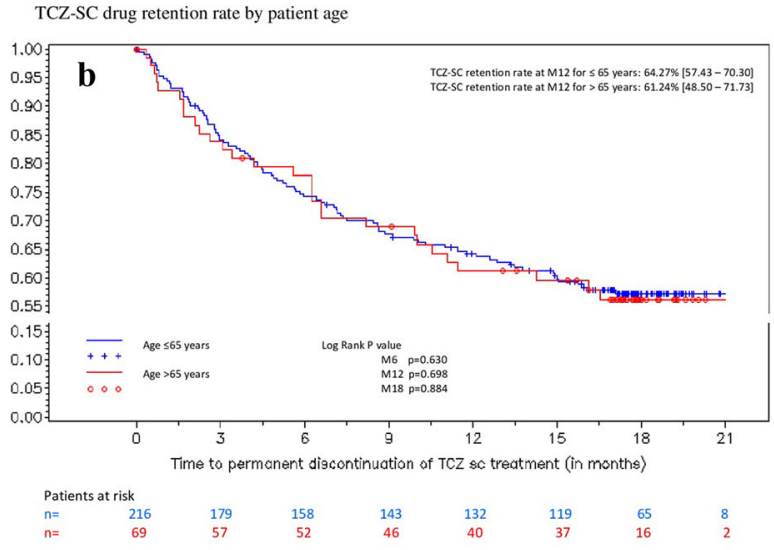

TCZ-SC retention rate by weekly MTX dose

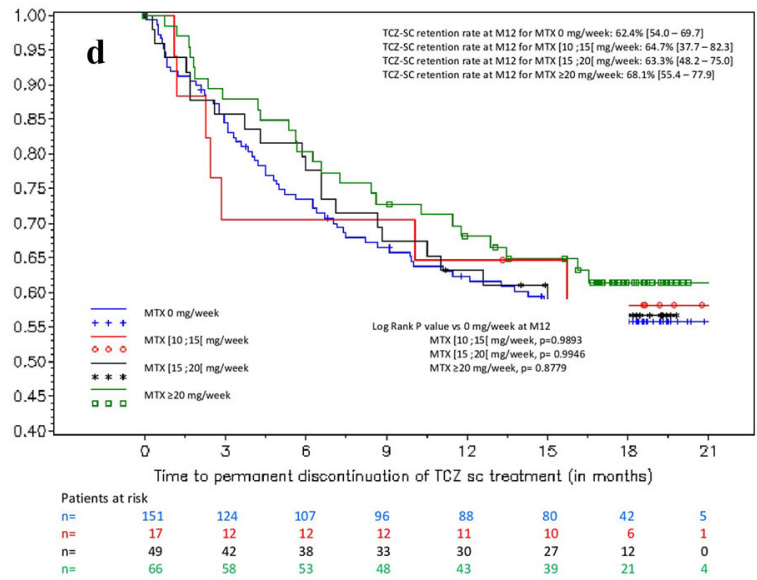

retention rate by patient age. $\mathbf{c}$ TCZ-SC drug retention rate by patient BMI. $\mathbf{d}$ TCZ-SC retention rate by weekly MTX dose (see Table 1 for corresponding interval boundaries)

\section{DISCUSSION}

Since drug retention usually reflects efficacy, tolerability, and patient satisfaction, particularly in real-life conditions, this real-world study mainly aimed to estimate the TCZ-SC retention rate at 12 months in patients with moderate to severe active RA.

This drug retention rate was estimated to be 64\% (95\% CI [58-69\%]), without significant differences according to baseline patient characteristics and RA treatment (age \pm 65 years, BMI, TCZ-SC as monotherapy or combination therapy, weekly MTX dose). In addition, 
Table 3 RA activity changes by classes during the study: efficacy population $(N=285)$

\begin{tabular}{|c|c|c|c|c|c|}
\hline$N(\%)$ & Baseline & Month 3 & Month 6 & Month 12 & Month 18 \\
\hline DAS28-ESR & $(n=252)$ & $(n=202)$ & $(n=154)$ & $(n=118)$ & $(n=86)$ \\
\hline Clinical remission* & $8(3.2)$ & $128(63.4)$ & $105(68.2)$ & $85(72.0)$ & $71(82.6)$ \\
\hline Low disease activity ${ }^{\#}$ & $22(8.7)$ & $149(73.8)$ & $127(82.5)$ & $102(86.4)$ & 79 (91.9) \\
\hline SDAI & $(n=246)$ & $(n=181)$ & $(n=140)$ & $(n=99)$ & $(n=76)$ \\
\hline Clinical remission* & $2(0.8)$ & $26(14.4)$ & $30(21.4)$ & $29(29.3)$ & $27(35.5)$ \\
\hline Low disease activity ${ }^{\#}$ & $18(7.3)$ & $107(59.2)$ & $88(62.8)$ & $75(75.8)$ & $67(88.1)$ \\
\hline CDAI & $(n=256)$ & $(n=195)$ & $(n=147)$ & $(n=104)$ & $(n=85)$ \\
\hline Clinical remission* & $2(0.8)$ & $24(12.3)$ & $30(20.4)$ & $28(26.9)$ & $28(32.9)$ \\
\hline Low disease activity ${ }^{\#}$ & $23(9.0)$ & $111(56.9)$ & $90(61.2)$ & $78(75.0)$ & $73(85.8)$ \\
\hline HAQ-DI & $(n=261)$ & - & $(n=134)$ & $(n=98)$ & - \\
\hline Mean \pm SD & $1.32 \pm 0.69$ & - & $0.93 \pm 0.77$ & $0.72 \pm 0.63$ & - \\
\hline
\end{tabular}

CDAI Clinical Disease Activity Index, DAS28-ESR Disease Activity Score 28 joints-Erythrocyte Sedimentation Rate, HAQ$D I$ Health Assessment Questionnaire-Disability Index, $S D$ standard deviation, SDAI Simplified Disease Activity Index ${ }^{*}$ Clinical remission thresholds: DAS28-ESR $<2.6$; SDAI $\leq 3.3$; CDAI $\leq 2.8$

\# Low disease activity thresholds: DAS25-ESR $\leq 3.2$; SDAI $\leq 11$; CDAI $\leq 10$. HAQ-DI was not evaluated at months 3 and 18

patients showed improvements in disease activity with a glucocorticoid-sparing effect with the TCZ-SC treatment. These outcomes are consistent with the improvement observed in patient's quality of life. The drug effectiveness was also reflected by the high rate of high adherers to TCZ-SC.

TCZ-SC was well tolerated, and the safety profile was consistent with the known profile of TCZ, with no differences according to the age of the treated patients ( \pm 65 years).

The representativeness of the participant clinicians should be assessed considering the mandatory hospital initiation of TCZ-SC treatment in France which resulted in only a few exclusively office-based rheumatologists having followed patients after the first TCZ-SC injection. Considering the median [Q1; Q3] recruitment by physicians, principal sites or satellite sites $(2[1 ; 4]$ for principal sites and $1[1 ; 1]$ for satellite sites respectively), inclusion of only one patient per center probably has no effect on study outcome. Patient and RA characteristics observed in the TANDEM study were broadly similar when compared to other non-interventional and interventional studies that assessed TCZ-IV and TCZ-SC [8-11, 21]. Although women might have a poorer response to treatment in RA [22], typically $75-80 \%$ of patients with RA are women, which is a classical feature in RA; therefore, the $75 \%$ female population in our study does not affect the transposability of our results to RA in general. Nevertheless, as regularly observed between interventional and observational studies, a slightly more severe baseline RA activity was observed in the TOZURA phase IV study [22] focusing on the SC formulation of TCZ than in the TANDEM study (DAS28-ESR $5.8 \pm 1.2$ vs. $4.8 \pm 1.2$, respectively) even if a lower proportion of patients had received prior bDMARD treatment (19\% vs. $63 \%$, respectively).

The drug retention rate of the TANDEM study at month 12 (64\%) was close to previous findings with TCZ-IV and close to what was found for other biological agents (between 64\% 
Table 4 Summary of all adverse events according to patient age: safety population $(N=286)$

\begin{tabular}{|c|c|c|c|c|c|c|}
\hline & \multicolumn{2}{|c|}{ Age $\leq 65$ years, $N=216$} & \multicolumn{2}{|c|}{ Age $>65$ years, $N=70$} & \multicolumn{2}{|c|}{ All patients, $N=286$} \\
\hline & Events, $n$ & Patients, $n(\%)$ & Events, $n$ & Patients, $n(\%)$ & Events, $n$ & Patients, $n(\%)$ \\
\hline \multicolumn{7}{|l|}{ Adverse events } \\
\hline At least one $\mathrm{AE}$ & 543 & $175(81.0)$ & 186 & $59(84.3)$ & 729 & $234(81.8)$ \\
\hline $\begin{array}{l}\text { At least one AE related to } \\
\text { TCZ-SC* }\end{array}$ & 237 & $121(56.0)$ & 79 & $40(57.1)$ & 316 & $161(56.3)$ \\
\hline \multicolumn{7}{|l|}{ Serious adverse events } \\
\hline At least one SAE & 42 & $31(14.4)$ & 23 & $15(21.4)$ & 65 & $46(16.1)$ \\
\hline $\begin{array}{l}\text { At least one SAE related to } \\
\text { TCZ-SC* }\end{array}$ & 23 & $18(8.3)$ & 9 & $7(10.0)$ & 32 & $25(8.7)$ \\
\hline \multicolumn{7}{|l|}{ Adverse events of special interest ${ }^{\#}$} \\
\hline At least one AESI & 278 & $139(64.4)$ & 97 & $52(74.3)$ & 375 & $191(66.8)$ \\
\hline $\begin{array}{l}\text { At least one AESI related* to } \\
\text { TCZ-SC }\end{array}$ & 144 & $91(42.1)$ & 54 & $36(51.4)$ & 198 & $127(44.4)$ \\
\hline \multicolumn{7}{|c|}{ Serious adverse events of special interest } \\
\hline At least one SAESI & 22 & $21(9.7)$ & 8 & $7(10.0)$ & 30 & $28(9.8)$ \\
\hline $\begin{array}{l}\text { At least one SAESI related* to } \\
\text { TCZ-SC }\end{array}$ & 16 & $15(6.9)$ & 5 & $4(5.7)$ & 21 & $19(6.6)$ \\
\hline
\end{tabular}

$A E$ adverse event, $A E S I$ AE of special interest, $S A E$ serious AE, $S A E S I$ serious AESI, TCZ-SC subcutaneous tocilizumab administration

*In case of missing information about causal relationship with TCZ-SC, the AE was considered as related to treatment

\# AESIs: anaphylaxis/hypersensitivity reactions, demyelinating disorders, gastrointestinal perforations, malignancies, myocardial infarctions, strokes, and serious and/or medically significant infections, hepatic events, and bleeding events

and $71 \%)[10,11,18]$. When focusing on the subcutaneous formulation, TANDEM drug retention rate at 1 year is also close to what is found with anti-tumor necrosis factor (TNF) or non-anti-TNF subcutaneous bDMARD, results of which vary from $62 \%$ to $73 \%$ [23-26]. Since some parameters could influence the effectiveness of the treatment and then potentially the drug persistence over time, drug retention was also analyzed according to the baseline characteristics of the patients (age and BMI), the use of TCZ-SC at first injection (monotherapy or combination with a csDMARD), and the weekly dose of MTX at first injection. No differences were observed either according to the use of TCZ-SC (MONO vs. COMBO, $p=0.725$ ), patient age ( \pm 65 years, $p=0.698$ ), nor the weekly dose of MTX. Regarding BMI, although it might be due to the number of patients, no significant relation was observed with TCZ-SC drug retention $\left( \pm 30 \mathrm{~kg} / \mathrm{m}^{2}, \quad p=0.496\right)$ as previously shown for effectiveness and body weight in non-interventional studies conducted in patients with RA switching from IV to SC formulations of TCZ $[27,28]$. Finally, no differences were observed between patient subgroups, indicating that the treatment duration of TCZ-SC, understood as an "indicator" of TCZ-SC effectiveness, is independent from patient characteristics and drug use.

No differences in retention rates were observed at month 6 between MONO and 
COMBO patients in the TANDEM study (74\% vs. $76 \%$, respectively, $p=0.717$ ). In the recent TOZURA study, a higher TCZ-SC retention rate was shown at month 6 , in particular for COMBO patients $(87 \%$ vs. $81 \%$ in $\mathrm{MONO}$ patients, $p=0.002$ ) [21]. The lower retention rates observed in TANDEM may be explained by the non-interventional design of the study, with less control in patient monitoring than in a clinical trial. In addition, differences in persistence between MONO and COMBO patients in the TOZURA study may be due to patient characteristics: MONO patients were more likely to have received prior bDMARD treatments and less likely to receive glucocorticoids at baseline compared with COMBO patients.

RA treatment discontinuation is usually driven by the lack of improvement or aggravation of the disease, even if there might be other reasons (drug toxicity, patient refusal to continue, etc.). As expected, the TANDEM study confirms the efficacy of TCZ-SC in real-world conditions, as previously demonstrated in phase III clinical trials [12-14], and in the TOZURA phase IV study [21]. In addition, a glucocorticoid-sparing effect was observed with TCZ-SC treatment, similar to that previously shown in a non-interventional study conducted in patients with RA treated with TCZ-IV [11].

During the TANDEM study, at least one AE and one SAE were reported in $82 \%$ and $16 \%$ of patients, respectively. In the previous 6-month phase III studies on TCZ-SC treatment, these respective proportions ranged from 63\% to 90\% and from $5 \%$ to $7 \%[12-14]$. In the recent 6-month TOZURA study [21], a similar proportion of patients with at least one SAE was observed (6\%).

The overall SAE rate observed in the TANDEM study was 21.4/100 PY, and the rate for serious infections and infestations, the most common SAE reported ( $22 \%$ of patients), was $4.3 / 100$ PY. These rates were higher than in the TOZURA study (14.6/100 PY and 3.6/100 PY, respectively) [21], but similar to those of the TCZ registry REGATE for serious infections and infestations (4.7/100 PY) [29].

At least one injection site reaction was reported in only $6 \%$ of patients, and only one local reaction led to treatment discontinuation.
Since patients over the age of 65 years are considered frailer than younger patients, safety analyses were conducted according to this age threshold. No relevant differences between patient groups were observed for AEs related to TCZ-SC $\quad(\leq 65$ years, $\quad 56 \%$ of patients; $>65$ years, $57 \%)$, related SAEs ( $8 \%$ and $10 \%$, respectively), and serious AESIs (10\% in both age groups). These findings were consistent with a previous study showing no differences in drug retention and adverse event discontinuation rates in tocilizumab-treated patients over or under 65 years old [30]. It is also consistent with the known TCZ profile and no new safety issues were identified.

Limitations of the TANDEM study were those of observational studies, with medical visits and physician and patient assessments not always performed at all the follow-up study times, with less data requested when compared to clinical trials, which might limit the interpretation of results. However, observational studies provide important, additional information in real-life conditions for unselected patients.

\section{CONCLUSION}

In the TANDEM study conducted in real-world in patients with RA starting TCZ-SC treatment, the estimated drug retention rate at month 12 was $64 \%$ (95\% CI [58-69\%]), confirming previous findings from interventional studies. No differences were observed according to patient profile (age and BMI), TCZ-SC use (monotherapy or combination with a csDMARD) or various weekly methotrexate doses for COMBO patients. The safety profile of TCZ-SC was consistent with previous interventional studies that assessed this drug formulation.

TCZ-SC provides a convenient administration option for patients with RA whatever their characteristics, allowing them to self-administer the drug, particularly in the ambulatory setting. Furthermore, when considering the costs of the TCZ intravenous administration, TCZ-SC should be preferred. 


\section{ACKNOWLEDGEMENTS}

The authors would like to thank all the rheumatologists and patients for their participation in the TANDEM study.

Funding. Sponsorship for this study and Rapid Service Fee were funded by Roche SAS and Chugai Pharma France.

Medical Writing, Editorial and Other Assistance. Assistance funded by Roche was provided by ICTA (Lise Guichard, logistic services and monitoring), KEYRUS (Ségolène Pastouret, statistical analyses), and AUXESIA (Dr. Marie-Odile Barbaza, manuscript preparation under the direction of the authors).

Authorship. All named authors meet the International Committee of Medical Journal Editors (ICMJE) criteria for authorship for this article, take responsibility for the integrity of the work as a whole, and have given their approval for this version to be published.

Disclosures. Pascal Hilliquin, Thomas Barnetche, Guy Baudens and Alain Saraux are members of the scientific committee of the TANDEM study and as such received honoraria from Roche. Alain Saraux is also a member of the journal's Editorial Board. Athan Baillet, René-Marc Flipo, Eric Lespessailles, Christian Roux, Patrice Fardellone, Arnaud Constantin, Emilie Shipley have nothing to disclose. Anika Gilbert Marceau is a Roche employee. Isabelle Idier is a Chugai Pharma France (Roche group) employee.

Compliance with Ethics Guidelines. According to French legislation regarding non-interventional studies, the TANDEM protocol (NCT02608112) was approved by the "Comite Consultatif sur le Traitement de l'Information en Matière de Recherche dans le Domaine de la Santé" (Consultative Committee on Information Processing for Research in the Field of Health) and by the Ethic Committee "Commission Nationale de l'Informatique et des Libertés" (Independent Administrative Authority Protecting Privacy and Personal Data) (authorization DR-2015-415), which guarantees confidentiality to the subjects. All patients were informed about the study before enrollment and had no objection to sharing their data. This study was performed in accordance with the Helsinki Declaration of 1964 and its later amendments.

Data Availability. The datasets generated during and/or analyzed during the current study are available from the corresponding author on reasonable request.

Open Access. This article is licensed under a Creative Commons Attribution-NonCommercial 4.0 International License, which permits any non-commercial use, sharing, adaptation, distribution and reproduction in any medium or format, as long as you give appropriate credit to the original author(s) and the source, provide a link to the Creative Commons licence, and indicate if changes were made. The images or other third party material in this article are included in the article's Creative Commons licence, unless indicated otherwise in a credit line to the material. If material is not included in the article's Creative Commons licence and your intended use is not permitted by statutory regulation or exceeds the permitted use, you will need to obtain permission directly from the copyright holder. To view a copy of this licence, visit http:// creativecommons.org/licenses/by-nc/4.0/.

\section{REFERENCES}

1. Emery P, Keystone E, Tony HP, et al. IL-6 receptor inhibition with tocilizumab improves treatment outcomes in patients with rheumatoid arthritis refractory to anti-tumour necrosis factor biologicals: results from a 24-week multicentre randomised placebo-controlled trial. Ann Rheum Dis. 2008;67: 1516-23 ([Erratum]. Ann Rheum Dis. 2009; 68:296).

2. Genovese MC, McKay JD, Nasonov EL, et al. Interleukin-6 receptor inhibition with tocilizumab reduces disease activity in rheumatoid arthritis with inadequate response to disease-modifying antirheumatic drugs: the tocilizumab in combination with traditional disease-modifying antirheumatic 
drug therapy study. Arthritis Rheum. 2008;58: 2968-80.

3. Smolen JS, Beaulieu A, Rubbert-Roth A, et al. Effect of intreleukin- 6 receptor inhibition with tocilizumab in patients with rheumatoid arthritis (OPTION study): a double-blind, placebo controlled randomised trial. Lancet. 2008;371:987-97.

4. Jones G, Sebba A, Gu J, et al. Comparison of tocilizumab monotherapy versus methotrexate monotherapy in patients with moderate to severe rheumatoid arthritis: the AMBITION study. Ann Rheum Dis. 2010;69:88-96.

5. Kremer JM, Blanco R, Brzosko M, et al. Tocilizumab inhibits structural joint damage in rheumatoid arthritis patients with inadequate responses to methotrexate: results from the double-blind treatment phase of a randomized placebo-controlled trial of tocilizumab safety and prevention of structural joint damage at one year. Arthritis Rheum. 2011;63:609-21.

6. Nishimoto N, Hashimoto J, Miyasaka N, et al. Study of active controlled monotherapy used for rheumatoid arthritis, an IL-6 inhibitor (SAMURAI): evidence of clinical and radiographic benefit from an $\mathrm{x}$ ray reader-blinded randomised controlled trial of tocilizumab. Ann Rheum Dis. 2007;66:1162-7.

7. Nishimoto N, Miyasaka N, Yamamoto $\mathrm{K}$, et al. Study of active controlled tocilizumab monotherapy for rheumatoid arthritis patients with an inadequate response to methotrexate (SATORI): significant reduction in disease activity and serum vascular endothelial growth factor by IL-6 receptor inhibition therapy. Mod Rheumatol. 2009;19:12-9.

8. Gabay C, Ryek M, Helland ML, et al. Effectiveness of tocilizumab with and without synthetic diseasemodifying antirheumatic drugs in rheumatoid arthritis: results from a European collaborative study. Ann Rheum Dis. 2016;75:1336-42.

9. Iking-Konert $\mathrm{C}$, von Hinübert $\mathrm{U}$, Richter $\mathrm{C}$, et al. ROUTINE-a prospective, multicentre, non-interventional, observational study to evaluate the safety and effectiveness of intravenous tocilizumab for the treatment of active rheumatoid arthritis in daily practice in Germany. Rheumatology. 2016;55: 624-35.

10. Flipo RM, Maillefert JF, Chazerain P, Idier I, Coudert M, Tebib J. Factors influencing the use of tocilizumab as monotherapy in patients with rheumatoid arthritis in a real-life setting: results at 1 year of the ACT-SOLO study. RMD Open. 2017;3:e000340.

11. Saraux A, Rouanet S, Flipo RM, et al. Glucocorticoid-sparing in patients suffering from rheumatoid arthritis and treated with tocilizumab: the SPARE-1 study. Clin Exp Rheumatol. 2016;34:303-10.

12. Burmester GR, Rubbert-Roth A, Cantagrel A, et al. A randomised, double-blind, parallel-group study of the safety and efficacy of subcutaneous tocilizumab versus intravenous tocilizumab in combination with traditional disease-modifying antirheumatic drugs in patients with moderate to severe rheumatoid arthritis (SUMMACTA study). Ann Rheum Dis. 2014;73:69-74.

13. Kivitz A, Olech E, Borofsky M, et al. Subcutaneous tocilizumab versus placebo in combination with disease-modifying antirheumatic drugs in patients with rheumatoid arthritis. Arthritis Care Res. 2014;66:1653-61.

14. Ogata A, Tanimura K, Sugimoto T, et al. Phase III study of thee and safety of subcutaneous versus intravenous tocilizumab monotherapy in patients with rheumatoid arthritis. Arthritis Care Res. $2014 ; 66: 344-54$.

15. Hishitani Y, Ogata A, Shima Y, et al. Retention of tocilizumab and anti-tumor necrosis factor drugs in the treatment of rheumatoid arthritis. Scand J Rheumatol. 2013;42:253-9.

16. Soliman MM, Ashcroft DM, Watson KD, et al. Impact of concomitant use of DMARDs on the persistence with anti-TNF therapies in patients with rheumatoid arthritis: results from the British Society for Rheumatology Biologics Register. Ann Rheum Dis. 2011;70:583-9.

17. Du Pan SM, Scherer A, Gabay C, Finckh A. Differential drug retention between anti-TNF agents and alternative biological agents after inadequate response to an anti-TNF agent in rheumatoid arthritis patients. Ann Rheum Dis. 2012;71:997-9.

18. Leffers HC, Ostergaard M, Glintborg B, et al. Efficacy of abatacept and tocilizumab in patients with rheumatoid arthritis treated in clinical practice: results from the nationwide Danish DANBIO registry. Ann Rheum Dis. 2011;70:1216-22.

19. Kobayakawa T, Kojima T, Takahashi N, et al. Drug retention rates of second biologic agents after switching from tumor necrosis factor inhibitors for rheumatoid arthritis in Japanese patients on lowdose methotrexate or without methotrexate. Mod Rheumatol. 2015;25:251-6.

20. Frazier-Mironer A, Dougados M, Mariette X, et al. Retention rates of adalimumab, etanercept and infliximab as first and second-line biotherapy in patients with rheumatoid arthritis in daily practice. Jt Bone Spine. 2014;81:352-9. 
21. Choy E, Caporali R, Xavir R, et al. Subcutaneous tocilizumab in rheumatoid arthritis: findings from the common-framework phase 4 study programme TOZURA conducted in 22 countries. Rheumatology. 2018;57:499-507.

22. Jawaheer D, Messing S, Reed G, et al. Significance of sex in achieving sustained remission in the consortium of rheumatology researchers of North America cohort of rheumatoid arthritis patients. Arthritis Care Res. 2012;64:1811-8.

23. Ebina K, Hashimoto H, Yamamoto W, et al. Drug retention and discontinuation reasons between seven biologics in patients with rheumatoid arthritis-The ANSWER cohort study-. PLoS One. 2018;13(3):e0194130.

24. Souto A, Maneiro JR, Gomez-Reino JJ. Rate of discontinuation and drug survival of biologic therapies in rheumatoid arthritis: a systematic review and meta-analysis of drug registries and health care databases. Rheumatology. 2016;55(3):523-34.

25. Flipo RM, Tubach F, Goupille P, et al. Real-life persistence of golimumab in patients with chronic inflammatory rheumatic diseases: results of the 2-year observational GO-PRACTICE study. Clin Exp Rheumatol. 2020. (Online ahead of print).
26. Saraux A, Flipo RM, Fagnani F, et al. Early non-response to certolizumab pegol in rheumatoid arthritis predicts failure to achieve low disease activity at 1 year: data from a prospective observational study. RMD Open. 2020;6(1):e000991.

27. Iwamoto N, Fukui S, Umeda M, et al. Evaluation of switching from intravenous to subcutaneous formulation of tocilizumab in patients with rheumatoid arthritis. Mod Rheumatol. 2016;26:662-6.

28. Darloy J, Segaud N, Salmon JH, et al. Tocilizumab effectiveness after switching from intravenous to subcutaneous route in patients with rheumatoid arthritis: the RoSwitch Study. Rheumatol Ther. 2019;6:61-75.

29. Morel J, Constantin A, Baron G, et al. Risk factors of serious infections in patients with rheumatoid arthritis treated with tocilizumab in the French Registry REGATE. Rheumatology. 2017;56:1746-54.

30. Pers YM, Schaub R, Constant E, et al. Efficacy and safety of tocilizumab in elderly patients with rheumatoid arthritis. Jt Bone Spine. 2015;82:25-30. 